BIOMEDICA

Vol. 6, Nos. 1 y $2-1986$

\title{
MEDIO SELECTIVO PARA EL AISLAMIENTO DE MICOBACTERIAS
}

\author{
ZULMA YOLANDA ORJUELA*, LUIS CARLOS OROZCO VARGAS**
}

\begin{abstract}
Se investigaron diferentes mezclas de antibióticos para producir un medio selectivo para aislar micobacterias, utilizando como base el medio de Ogawa-Kudoh (O-K).
\end{abstract}

Se encontró que la mezcla penicilina-ácido nalidixico-cicloheximida y cristal violeta inhibian el mayor porcentaje de contaminantes.

La mayoría de las especies de micobacterias también fueron inhibidas parcial o totalmente a excepción del M. tuberculosis.

\section{INTRODUCCION}

La contaminación de los cultivos que se utilizan para el aislamiento de micobacterias es un problema frecuente, a pesar de que las muestras sufren un proceso de decontaminación con soda y los medios de cultivo contienen verde de malaquita (1).

Debido a esta contaminación, Lorian-Maddock (2), Petran-Vera (3), Mitchison, Allen y Lambert (4) entre otros, han trabajado con medios selectivos, que son medios de cultivo a los cuales se les agregan sustancias que inhiben microorganismos diferentes al gérmen que se desea aislar. Con base en sus experiencias, hicimos un estudio para determinar un medio selectivo que inhibiera los gérmenes contaminantes más comunes encontrados en nuestro laboratorio, sin que se afectara el desarrollo de las micobacterias.

Se prepararon tres medios selectivos utilizando como base el Ogawa-Kudoh (O-K) (5) y se sembraron 65 cepas de microorganismos aislados de cultivos contaminados y se comparó el efecto inhibitorio de los tres medios selectivos. Además, se sembraron también diferentes micobacterias para observar la inhibición que dichos medios podrían ejercer sobre su crecimiento.

\section{MATERIALES Y METODOS}

\section{Medios Selectivos}

Para la preparación de los medios selectivos se tuvo como base el medio de O-K (5) al cual se le agregaron diferentes agentes selectivos (ver tabla 1).

TABLA NN I

CONCENTRACION DE LOS AGENTES SELECTIVOS EN LOS DIFERENTES MEDIOS

\begin{tabular}{|l|c|c|c|}
\hline $\begin{array}{c}\text { Concentración de los } \\
\text { agentes selectivos } \\
\text { (ug/ml) }\end{array}$ & OK $_{\mathrm{A}}$ & OK $_{\mathrm{B} 1}$ & OK $_{\mathrm{B} 2}$ \\
\hline LINCOMICINA & 2 & & \\
\hline PENICILINA & & 200 & 500 \\
\hline ACIDO NALIDIXICO & 35 & 35 & 35 \\
\hline CICLOHEXIMIDA & 400 & 400 & 400 \\
\hline CRISTAL VIOLETA & 1.5 & 1.5 & 1.5 \\
\hline
\end{tabular}

\section{Inhibición de los Gérmenes Contaminan- tes en los Diferentes Medios Selectivos}

Se tomaron cultivos contaminados provenientes de muestras de pacientes y de medio ambiente se hicieron aislamientos de los gérmenes contaminantes en agar chocolate y Sabouraud según correspondiera.

\footnotetext{
* Bacterióloga rural Grupo de Micobacterias, Instituto Nacional de Salud.

**Jefe Grupo de Micobacterias, Instituto Nacional de Salud.

Solicitud reimpresos: Luis Carlos Orozco Vargas, Apartado Aéreo No. 80334 INS. Bogotá.
} 
Z.Y. ORJUELA, L.C. OROZCO

TABLA № 2

MICROORGANISMOS CONTAMINANTES

ESTUDIADOS SEGUN PROCEDENCIA

\begin{tabular}{|c|c|c|c|c|c|}
\hline \multirow{2}{*}{ MUESTRAS } & \multicolumn{5}{|c|}{ MICROORGANISMOS CONTAM INANTES } \\
\cline { 2 - 6 } & $\begin{array}{c}\text { Bacilos } \\
\text { Gram (+) }\end{array}$ & $\begin{array}{c}\text { Bacilos } \\
\text { Esporul. } \\
\text { Gram (+) }\end{array}$ & $\begin{array}{c}\text { Cocos } \\
\text { Gram (+) }\end{array}$ & $\begin{array}{c}\text { Bacilos } \\
\text { Gram (-) }\end{array}$ & $\begin{array}{c}\text { Mohos } \\
\text { Levad. }\end{array}$ \\
\hline $\begin{array}{c}\text { PACIENTES * } \\
\text { N = 52 }\end{array}$ & 17 & 6 & 12 & 15 & 2 \\
\hline $\begin{array}{c}\text { MEDIO AMBIENTE** } \\
\text { N = 13 }\end{array}$ & 2 & 6 & 1 & 3 & 1 \\
\hline TOTAL & 19 & 12 & 13 & 18 & 3 \\
\hline
\end{tabular}

* = Orinas, lavados gástricos, esputos, ełc.

** $=$ Heces de cabra, peces de agua dulce.

TABLA № 3

CONTAMINANTES ESTUDIADOS Y SU INHIBICION POR LOS TRES MEDIOS SELECTIVOS

\begin{tabular}{|c|c|c|c|c|c|c|c|}
\hline \multirow{2}{*}{\multicolumn{2}{|c|}{$\begin{array}{l}\text { GERMENES } \\
\text { ESTUDIADOS }\end{array}$}} & \multicolumn{6}{|c|}{ INHIBIDOS POR } \\
\hline & & \multicolumn{2}{|c|}{$\mathrm{OK}_{A}$} & \multicolumn{2}{|c|}{$\mathrm{OK}_{\mathrm{B} 1}$} & \multicolumn{2}{|c|}{$\mathrm{OK}_{\mathrm{B} 2}$} \\
\hline B.G. $(+)$ & 19 & 11 & (57.9) & 11 & (57.9) & 13 & $(68.4)$ \\
\hline B.G. (+) E. & 12 & 5 & $(41.7)$ & 9 & $(75.0)$ & 9 & $(75.0)$ \\
\hline C.G. $(+)$ & 13 & 5 & (38.5) & 8 & $(6 \mid .5)$ & 8 & $(6 \mid .5)$ \\
\hline B.G. $(-)$ & 18 & 11 & $(61.1)$ & 15 & (83.3) & 15 & (83.3) \\
\hline Mohos / lev. & 3 & 3 & $(100.0)$ & 3 & $(100.0)$ & 3 & $(100.0)$ \\
\hline $\begin{array}{c}\text { TOTAL } \\
\%\end{array}$ & $\begin{array}{r}65 \\
100\end{array}$ & 35 & $(53.8)$ & 46 & $(70.7)$ & 48 & $(73.8)$ \\
\hline
\end{tabular}


De un total de 65 cepas, 52 correspondían a muestras de pacientes y 13 a muestras de medio ambiente (ver tabla 2).

Una vez aislados, se sembraron por estrias en los medios selectivos. Se incubaron a $37^{\circ} \mathrm{C}$ y se hicieron lecturas a las $24,48,72$ horas y a los 8 y 15 días.

\section{Inhibición de las Micobacterias en los Me- dios Selectivos}

Después de conocer los resultados de la inhibición de los contaminantes, se seleccionaron los dos medios que dieron mayor inhibición para investigar su poder inhibitorio sobre varias micobacterias cuya lista aparece en la tabla 4.

TABLA № 4

MICOBACTERIAS ESTUDIADAS $Y$ SU INHIBICION POR LOS MEDIOS OKB 1 Y OKB2

\begin{tabular}{|c|c|c|c|}
\hline MICOBACTERIA & & $\begin{array}{c}\text { NO } \\
\text { INHIBIDAS }\end{array}$ & $\begin{array}{r}\text { INHIBIDAS } \\
90 \% \\
(100 \%) \\
\end{array}$ \\
\hline M. bovis, var. BCG & 1 & - & 1 \\
\hline M. tuberculosis & 3 & 3 & 0 \\
\hline M. tuberculosis (H37 Rv) & 3 & 3 & 0 \\
\hline M. simiae & I & 1 & 0 \\
\hline M. kansasii & 1 & - & 1 \\
\hline M. marinum & I & 1 & 0 \\
\hline M. scrofulaceum & I & - & 1 \\
\hline ‥ gordonae & 2 & - & 2 \\
\hline Mais & । & - & 1 \\
\hline M. gastri & 1 & - & $O(1)$ \\
\hline M. intracelullare & 1 & - & 1 \\
\hline M. avium & I & - & 1 \\
\hline M. fortuitum -chelonae & 10 & 6 & I (3) \\
\hline M. vaccae & 2 & - & 1 (I) \\
\hline M. phlei & 2 & - & 2 \\
\hline M. aurum & 1 & - & 1 \\
\hline M. dierhnoferi & 1 & - & $0(1)$ \\
\hline M. flavescens & 1 & - & 1 \\
\hline$\underline{\mathrm{M}} . \underline{\mathrm{s}} \mathrm{p}$. & 2 & - & $O(2)$ \\
\hline
\end{tabular}

\section{RESULTADOS}

La tabla 3 muestra los porcentajes de inhibición de los tres medios selectivos sobre los diferentes microorganismos contaminantes.

Las diferentes bacterias fueron inhibidas entre un $38.5 \%$ y un $83.3 \%$, por los tres medios selectivos.

Las bacterias menos inhibidas fueron los cocos Gram (+), las de mayor inhibición, los bacilos Gram $(-)$.

Los tres medios inhibieron las tres cepas de mohos y levaduras. El mayor porcentaje de inhibición fue dado por el OKB2, 73.8\%, seguido por el OKB1, $70.7 \%$.

Lo anterior llevó a evaluar los medios OKB1 y $\mathrm{OKB} 2$ con relación a las micobacterias.

En la tabla 4 se aprecian las cepas de micobacterias que fueron investigadas para evaluar su posible inhibición por los medios selectivos. Las únicas cepas que no fueron inhibidas por los medios fueron $M$. tuberculosis, M. simiae, M. marinum y 6 cepas de M. fortuitum-chelonae.

Las demás fueron inhibidas en más de un $90 \%$.

Una cepa de $M$. gastri, 3 de $M$. fortuitum-chelonae, una de $M$. vaccae, una de $M$. dierhnoferi y dos $\mathbf{M}$. sp. fueron inhibidas totalmente.

Las micobacterias que fueron parcialmente inhibidas mostraron este fenómeno en una mayor proporción en el OKB2.

\section{DISCUSION}

En el aislamiento de micobacterias, la contaminación de los cultivos ha preocupado a los investigadores. Es así, como a través de los años han venido trabajando con sustancias selectivas que se agregan a los medios de cultivo para inhibir microorganismos diferentes a las micobacterias. El verde de malaquita ha sido el más utilizado y está incluido en los medios a base de huevo, Lowenstein Jensen (L-J), Petragnani y Ogawa-Kudoh (O-K) (5). 
Rhines, en 1935 (6) utilizó cristal violeta a una concentración de $1.5 \mu \mathrm{g} / \mathrm{ml}$. en medios sólidos para inhibir flora Gram (+) de muestras donde buscaba aislar $M$. avium.

Ungar-Mugleton en 1946 (7) utilizaron penicilina en diferentes medios de cultivo y encontraron que no era tóxica para el $M$. tuberculosis.

Kirby-Dubos, en 1947 (8) comentaron que no se debería agregar penicilina a medios que contengan tween 80 , pues según sus experiencias el polisorbato incrementa la sensibilidad delM. tuberculosis a la penicilina.

Gruft, en 1965 (9) realizó un estudio agregando ácido nalidixico a diferentes concentraciones a medios de cultivo y encontró que a $35 \mu \mathrm{g} / \mathrm{ml}$. no se afectaba el crecimiento de las micobacterias y causaba una buena inhibición de los gérmenes Gram (-).

Aunque varios investigadores han utilizado mezcla de sustancias inhibidoras, la mayoría lo han hecho en medios que tienen como base el agar.

Solamente Petran y Vera (3) utilizaron L-J como base de su mezcla de agentes selectivos los cuales incluían ácido nalidixico, lincomicina y cicloheximida a las mismas concentraciones utilizadas en el presente estudio.

Nuestro medio selectivo OKA, era similar al Micobactosel $®$ de Petran y Vera y contenía cristal violeta además del verde de malaquita usual en el medio O-K.

A pesar de lo anterior, este medio dió el menor índice de inhibición de gérmenes contaminantes. Esta menor inhibición fue más aparente en los cocos Gram $(+)$ y bacilos Gram $(+) E$, lo que sugiere que la penicilina es más activa que la lincomicina en la inhibición de los gérmenes Gram (+) frecuentes como contaminantes, sin descartar la posibilidad de un fenómeno de sinergismo con las otras sustancias porque el fenómeno, aunque en menor proporción, también se observa con los bacilos Gram (-).

Al comparar la inhibición en los medios OKB1 y OKB2, cuya única diferencia es la concentración de penicilina $200 \mu \mathrm{g} / \mathrm{ml}$. en el primero y $500 \mu \mathrm{g} / \mathrm{ml}$. en el segundo, la diferencia observada está dada exclusivamente en el porcentaje de inhibición de bacilos Gram $(+)$.

$\mathrm{Al}$ ser estos dos medios OKB1 y OKB2 los que dieron una mayor inhibición de contaminantes, fueron seleccionados para evaluar el efecto que tendrían sobre las micobacterias.

Aunque algunas de las posibles patógenas fueron parcialamente inhibidas, sólo 3 cepas de $M$. fortuitumchelonae lo fueron totalmente. Sin embargo, la inhibición parcial fue más evidente en el OKB2 que contenía mayor concentración de penicilina $(500 \mu \mathrm{g} / \mathrm{ml}$.), lo que sugiere que algunas especies de micobacterias sean sensibles "in vitro" a concentraciones de penicilina de $500 \mu \mathrm{g} / \mathrm{ml}$. en presencia de tween $80 \mathrm{o}$ actuando en forma sinérgica con las otras sustancias.

La cicloheximida utilizada en los tres medios selectivos inhibió las cepas de levadura y la cepa de mohos. Esta es la sustancia recomendada por Petran y Vera (3), aunque algunos autores no encontraron dicha sustancia útil (10).

Por lo anterior, creemos que los medios selectivos pueden ser útiles cuando se intenta aislar $M$. tuberculosis, pero no parecen recomendables cuando se pretende aislar otras micobacterias.

Existe también la posibilidad de que la mezcla de sustancias inhibitorias permita diferenciar entre algunas especies similares, en especial el grupo de fotogromógenos y el complejo fortuitum-chelonae.

\section{SUMMARY}

Different mixtures of antibiotics were investigated to produce a selective medium for the isolation of mycobacteria, using Ogawa-Kudoh as the base medium.

It was founded that the mixture: penicillin-nalidixic acid-cicloheximide and cristal violet inhibited the highest percentage of contaminants. Most of the species of mycobacteria were also parcial or totally inhibited except M. tuberculosis. 


\section{BIBLIOGRAFIA}

1. Orozco, L.C., et al. El cultivo de esputo para el diagnóstico de tuberculosis pulmonar, Biomédica 1985; 5 : 24-25.

2. Lorian, V., Maddock. The effect of anticontamination agents in media for the isolation of mycobacteria. Dis. Ches. 1966; $50: 630-632$

3. Petran, E.I., Vera, H.D. Media for selective isolation of mycobacteria, Health Lab. Sci. 1971; 8 : 225-230.

4. Mitchison, DA, Allen, BW, Lambert, R.A. Selective media in the isolation of tubercle bacilli from tissues. J. Clin Pathol, $1973 ; 26: 250-252$

5. Orozco, LC, et al. Tuberculosis - Manual de Procedimientos. Pub. Cient. No. I 1985.
6. Rhines, C. The persistence of avian tubercle bacilli in soil and in association with soil microorganisms, J. Bacteriol, 1935; $29: 299-311$

7. Ungar, J., Muggleton, P. The effect of penicillin on the growth of human type $M$. tuberculosis. J. Pathol Bacteriol, 1946; 58 : 501-504.

8. Kirby, W.M.M., Dubos, R.J. Effect of penicillin on the tubercle bacillus in vitro. Proc. Soc. Exp. Biol. Med. 1947; 66 : $120-123$

9. Gruft, H. Nalidixic acid as a decontaminant in L-J medium. J. Bacteriol, 1965; $9: 829$

10. Corper, H.J., Cohn, M.L. Cycloheximide as a fungicide in solid media for growing tubercle bacilli from sputum, Antibiot Chemother (Basel), 1952; $2: 12-15$. 